\title{
Impact of Device Parameter Variation on the Electrical Characteristic of N-type Junctionless Nanowire Transistor with High-k Dielectrics
}

\author{
Mohammed Adamu Sule ${ }^{1}$, Mathangi Ramakrishnan², Nurul Ezaila Alias ${ }^{3}$, Norlina Paraman ${ }^{4}$, Zaharah \\ Johari $^{5}$, Afiq Hamzah ${ }^{6}$, Michael Loong Peng Tan ${ }^{7}$, Usman Ulllah Sheikh ${ }^{8}$ \\ ${ }^{1}$ Department of Computer Engineering Technology, ATAP Bauchi, Nigeria. \\ 2,3,4,5,6,7,8 School of Electrical Engineering, Faculty of Engineering, Universiti Teknologi Malaysia, Malaysia
}

\begin{tabular}{l} 
Article Info \\
\hline Article historys: \\
Received Jan 7, 2020 \\
Revised June 28, 2020 \\
Accepted June 30, 2020 \\
\hline
\end{tabular}

\section{Keywords:}

Junctionless Transsitor

Nanoware

High-k dielectrics

Inversion-mode

Silicon dioxide

\begin{abstract}
Metallurgical junction and thermal budget are serious constraints in scaling and performance of conventional metal-oxide-semiconductor field-effect transistor (MOSFET). To overcome this problem, junctionless nanowire fieldeffect transistor (JLNWFET) was introduced. In this paper, we investigate the impact of device parameter variation on the performance of n-type JLNWFET with high-k dielectrics. The electrical characteristic of JLNWFET and the inversion-mode transistor of different gate length $\left(\mathrm{LG}_{\mathrm{G}}\right)$ and nanowire diameter $\left(\mathrm{d}_{\mathrm{NW}}\right)$ was compared and analyzed. Different high-k dielectrics were used to get an optimum device structure of JLNWFET. The device was simulated using SDE Tool of Sentaurus TCAD and the I-V characteristics were simulated using Sdevice Tools. Lombardi mobility model and Philips unified mobility model were applied to define its electric field and doping dependent mobility degradation. A thin-film heavily doped silicon nanowire with a gate electrode that controls the flow of current between the source and drain was used. The proposed JLNWFET exhibits high ON-state current (ION) due to the high doping concentration $\left(\mathrm{N}_{\mathrm{D}}\right)$ of $1 \times 10^{19} \mathrm{~cm}^{-3}$ which leads to the improved ON-state to OFF-state current ratio (IoN/IOFF) of about $10 \%$ than the inversionmode device for a $L_{G}$ of $7 \mathrm{~nm}$ and the silicon $d_{N W}$ of $6 \mathrm{~nm}$. Electrical characteristics such are drain induced barrier lowering (DIBL) and subthreshold slope (SS) were extracted which leads to low leakage current as well as a high ION/IOFF ratio. The performance was improved by introducing silicon dioxide $\left(\mathrm{SiO}_{2}\right)$ with high-k dielectric materials, hafnium oxide $\left(\mathrm{HfO}_{2}\right)$ and silicon nitrate $\left(\mathrm{Si}_{3} \mathrm{~N}_{4}\right)$. It was found that JLNWFET with $\mathrm{HfO}_{2}$ exhibits better electrical characteristics and performance.
\end{abstract}

Copyright (C) 2019 Institute of Advanced Engineering and Science. All rights reserved.

\section{Corresponding Author:}

Nurul Ezaila Alias, School of Electrical Engineering,

Faculty of Engineering, Universiti Teknologi Malaysia, Malaysia.

Email: ezaila@utm.my

\section{INTRODUCTION}

To speed up the performance of the microprocessor, the number of transistors must be double in every 18 months. To double the number of transistors means to reduce the size of transistor. As what being predicted by Moore's law, process technology tends to be scaled down continuously [1]. The scaling process allowed more transistors to be packed in a smaller chip area and hence enhance the functionality of silicon on chips (SoCs). MOSFET typically used in industries due to its small size, and can be fabricated in a single integrated circuit with millions of numbers. However, the scaling of conventional planar transistor has reached its limit which lead to increase in short channel effects (SCEs) and sensitivity to process variation [2]. SCEs are the main limitations in the scaling of MOSFET below 10nm [3]. SCEs comprises of Drain Induced Barrier 
Lowering (DIBL), subthreshold slope (SS), limitation imposed on electron drift characteristics in the channel, increase in threshold voltage variation, reduction in $\mathrm{I}_{\mathrm{ON}} / \mathrm{I}_{\mathrm{OFF}}$ ratio and increase of leakage current causing the scaling of conventional CMOS transistors in sub 10nm technologies almost impossible. This is due to the fact that reduction in $\mathrm{I}_{\mathrm{ON}} / \mathrm{I}_{\mathrm{OFF}}$ ratio leads to device instability and hence limits subthreshold circuit design. Furthermore, increment in leakage current leads to the static power consumption increment[2].

In PN Junction transistor, the junction is formed when a piece of P-type silicon material and N-type piece of silicon are in contact. The majority carriers in N-type material are electrons, while holes are the majority carriers in P-type semiconductor. Some junction formed by two different semiconductors e.g. Schottky diode, heterojunction etc. Bipolar junction transistor contains two p-n junctions, JFET (junction fieldeffect transistor) has only one $\mathrm{p}-\mathrm{n}$ junction and MOSFET contains a Schottky junction [4]. Junctionless transistor (JLFET) was introduced to replace the traditional junction transistor because of the challenges in scaling and complex thermal budget of the device [5]. Junctionless transistors can be described as variable resistors controlled by a gate electrode. JLNWFET is a very thin heavily doped semiconductor nanowire that has gate electrode that control the flow of current from source to drain [6]. The gate oxide thickness has gradually decreased so as to increase the gate capacitance as well as to drive the current to increase the device performance [7].Nanowire transistor has a uniform heavily doping concentration from source to drain. The channel also has the same doping concentration that can be fully depleted to turn the device off.High doping concentration and ultra-shallow junction are the main obstacles in improving scaling in MOSFETs [8]. Short channel effects such as Drain Induced Barrier Lowering (DIBL), subthreshold Swing (SS) and so on reduces the performance of the device [9]. Junctionless transistors, also known as gated resistor, have no junctions hence, no doping concentration gradients, simpler fabrication process, diminished DIBL and SS, and better electrical properties. Short channel effects are significantly reduced in Junctionless transistor [10]. The properties of the material of the gate and channel wires in conjunction with the nanoscale geometries in metalgated junctionless FET (MJLFET) allows FET-like switching characteristics without the need for engineered source and drain junctions or lateral doping abruptness [11].

Previous work shows that Many researchers have contributed tremendously in identifying the challenges in scaling of conventional MOSFET. Junctionless FETs were proposed in order to overcome short channel and scaling challenges [12]. JLT exhibits excellent $\mathrm{I}_{\mathrm{ON}}-\mathrm{I}_{\mathrm{OFF}}$ ratio, improved the scaling to the sub region, decreasing the short channel effects (SCE) and better electrical properties. SCEs can be mitigated by reducing the electrostatic integrity factor which depends on the geometry of the device and it is a measure of the way the electric field lines from drain influence the channel region thus causing the SCEs [13]. Lowsidewalls can improve the SCEs of the device significantly by reducing the fringing-induced barrier lowering for thick-gate insulators [14].

Multigate junctionless transistor (MuGJLT) was compared with MOSFET for a gate length of 10 $30 \mathrm{~nm}$ has been conducted by Chi-Woo Lee et al.[9]. The electrical characteristics such as the DIBL, SS and threshold voltage $\left(\mathrm{V}_{\mathrm{TH}}\right)$ of both MuGJLT and MOSFET were evaluated and analyzed. In this study, DIBL and $\mathrm{SS}$ of MuGJLT were significantly improving better than the conventional MOSFET for different $\mathrm{L}_{\mathrm{G}}$. The SS of the device with $\mathrm{L}_{\mathrm{G}} 5 \mathrm{~nm}$ is below $80 \mathrm{mV} /$ decade which is better than that of the MOSFET. This shows the potential of JLT for extremely short-channel applications. The $\mathrm{I}_{\mathrm{OFF}}$ is determined entirely by the electrostatic control of the gate not by the leakage current of a reverse-biased diode. The drain current was high due to the high doping concentration of $8 \times 10^{19} \mathrm{~cm}^{-3}$ and the cross-sectional area of the silicon wire is too small compare to the IM which used lightly doped channel in order to avoid pre-matured inversion at the corners [9].The electrical properties of junctionless nanowire transistor (JNT), inversion-mode transistor and accumulationmode MOS devices for gate length 5nm were compared by J.P. Colinge et al.[15]. The variation of threshold voltage with physical parameters and intrinsic device performed was analyzed.

The drain current $I_{D S}$ was significantly increased even for a gate length of $10 \mathrm{~nm}$, but the leakage current is also high for $\mathrm{V}_{\mathrm{GS}}=0 \mathrm{~V}$. This shows the leakage current is high in nanowire junctionless transistor having thickness oxide, $t_{\mathrm{ox}}$ of $2 \mathrm{~nm}$. DIBL and SS were high for short $\mathrm{L}_{\mathrm{G}}$, but significant improved when the effective length, $L_{\text {eff }}$ was high i.e. when $L_{G}$ is $15 \mathrm{~nm}$ achieves a degraded SS of $78 \mathrm{mV} / \mathrm{dec}$ and DIBL of 95 $\mathrm{mV} / \mathrm{V}$ [15]. The electrical characteristics of Nanowire JLFET and core shell JLFET were compared in [16]. IOFF was improved by more than one order of magnitude when a high-k dielectric is used as a spacer in double gate junctionless transistor [17]. The leakage current has reduced due to parasitic bipolar junction transistor (BJT) action in the NWJLFET [18]. Core shell JLFET with the higher doping concentration has the lower leakage current is and therefore, exhibit higher $\mathrm{I}_{\mathrm{ON}} / \mathrm{I}_{\mathrm{OFF}}$ ratio. Although a core doping of $1 \times 10^{19} \mathrm{~cm}^{-3}$ depletes the shell region at core shell interface, but the depletion is not sufficient to volume depletion. Electron channel still exists in the channel region. Highly doped $\mathrm{p}+$ core of $1 \times 10^{20} \mathrm{~cm}^{-3}$ should be use in order to achieve total volume depletion [16]. The $\mathrm{I}_{\mathrm{OFF}}$ may be increases when the channel length in the NWJLFET due to the improved gain of the parasitic bipolar junction transistor (BJT) when the base width reduced [19, 20]. The parasitic BJT action causes the I IFF to increased, hence IoN/IOFF ratio decreases [21]. 
In this paper, JLNWFET device and the inversion mode FETs of the same device parameters was designed and their performances were compared and analyzed. JLNWFET device of different dielectric materials (low-k and high-k) was also designed and their electrical characteristics were compared and analyzed. The electrical properties such as threshold voltage $\left(\mathrm{V}_{\mathrm{th}}\right)$, on-off current ratio $\left(\mathrm{I}_{\mathrm{ON}} / \mathrm{I}_{\mathrm{OFF}}\right)$, subthreshold swing (SS), and drain induced barrier lowering (DIBL) were extracted from the I-V curves. Finally, their overall electrical characteristics were compared and validated with the literature review.

\section{RESEARCH METHOD}

The simulation was carried out using Sentaurus TCAD software. The device structure was simulated by using SDE Tool and I-V curve was extracted by using Sdevice Tool. Lombardi mobility model and Philips unified mobility model were embedded to consider field- and doping-dependent mobility degradation. Shockley-Read-Hall (SRH) is the dominant generation and recombination process in silicon and other indirect energy band gap materials. It can also dominate in direct band gap materials under conditions of very low carrier densities or very low level injection. Auger recombination model and Fermi-Dirac statistics were also used. The $L_{G}$ of the devices was varied between $7-120 \mathrm{~nm}$ and $\mathrm{d}_{\mathrm{NW}}$ was varied from $6-10 \mathrm{~nm}$ were designed and simulated. $\mathrm{SiO}_{2}$ and high-k dielectric materials such as $\mathrm{HfO}_{2}$ and $\mathrm{Si}_{3} \mathrm{~N}_{4}$ devices of different $\mathrm{L}_{\mathrm{G}}$ and $d_{N W}$ were also designed and simulated to obtained electrical characteristics. High-k dielectric was used in the JLNWFET device structure to optimize the electrical characteristics and reduce the SCEs. The electrical characteristics such as $\mathrm{V}_{\mathrm{TH}}$, ON-state current, OFF-state current, DIBL, SS and the ON-state to OFF-state current ratio of the devices were analyzed. The parameters and dimension of the device are shown in Table 1 for both the JLNWFET and Inversion-Mode device. The table shows the dimensions of the parameters used in designing the two devices of different $\mathrm{L}_{\mathrm{G}}$ and $\mathrm{d}_{\mathrm{NW}}$. The device parameters of JLNWFET is the same with that of [22] for further validation. Both devices JLNWFET and Inversion-Mode NWFET are fixed to have same device parameters.

Table 1. JLNWFET and Inversion-mode device parameters

\begin{tabular}{ccc}
\hline Parameter & JLNWFET & Inversion-mode \\
\hline Structure & n-type cylinderical & n-type cylindrical \\
S/D doping & $10^{19} \mathrm{~cm}^{-3}$ & $10^{17} \mathrm{~cm}^{-3}$ \\
Channel doping & $10^{19} \mathrm{~cm}^{-3}$ & $2 \times 10^{20} \mathrm{~cm}^{-3}$ \\
Nanowire diameter $\left(\mathrm{d}_{\mathrm{NW}}\right)$ & $6-10 \mathrm{~nm}$ & $6-10 \mathrm{~nm}$ \\
Oxide thickness $\left(\mathrm{t}_{\mathrm{ox}}\right)$ & $1 \mathrm{~nm}$ & $1 \mathrm{~nm}$ \\
Oxide material used & $\mathrm{SiO}_{2}, \mathrm{HfO}_{2}, \mathrm{Si}_{3} \mathrm{~N}_{4}$ & $\mathrm{SiO}_{2}$ \\
Gate workfunction $\left(\phi_{\mathrm{m}}\right)$ & $4.8 \mathrm{eV}$ & $4.8 \mathrm{eV}$ \\
Gate length $\left(\mathrm{L}_{\mathrm{G}}\right)$ & $7-120 \mathrm{~nm}$ & $7-120 \mathrm{~nm}$ \\
Length of S/D & $10 \mathrm{~nm}$ & $10 \mathrm{~nm}$ \\
(LSD) & & \\
Length of S/D contact & $10 \mathrm{~nm}$ & $10 \mathrm{~nm}$ \\
$(L S D C)$ & & \\
\hline
\end{tabular}
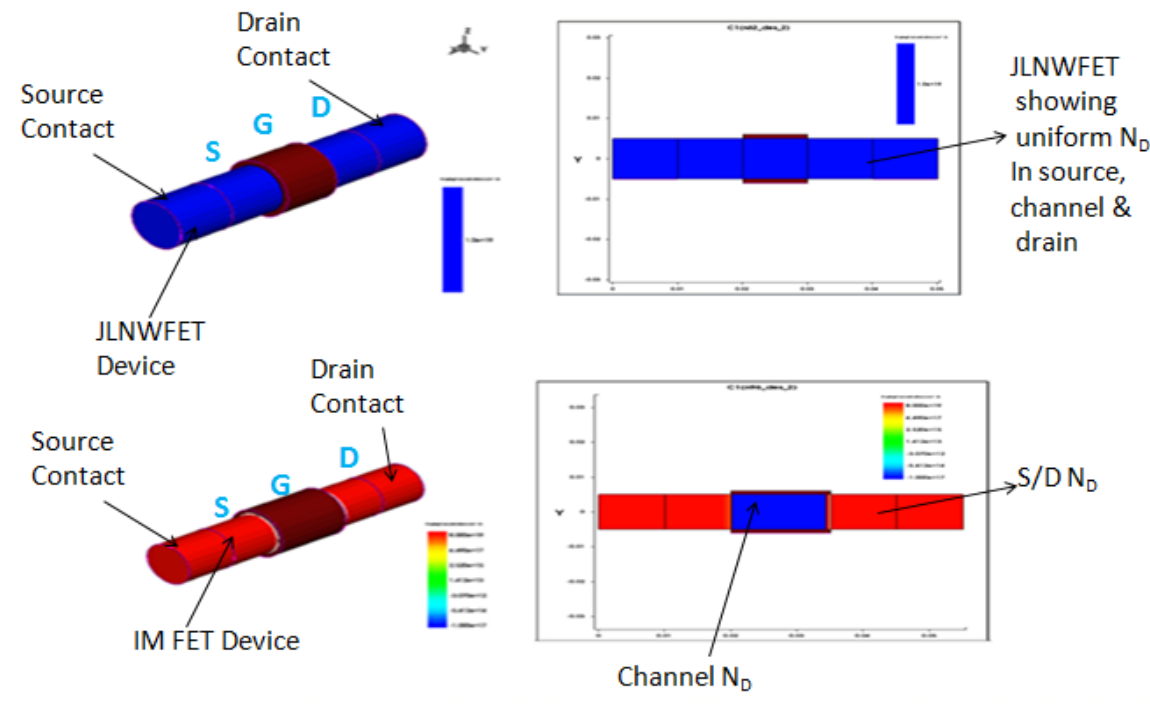

Figure 1. 3D and horizontal cross-sectional view of JLNWFET (top) and Inversion-mode (bottom) devices 
The 3D and horizontal cross-sectional diagram of JLNWFET and the inversion-mode device was shown in Figure 1. It shows that JLNWFET has uniform $\mathrm{N}_{\mathrm{D}}$ from source to drain while the inversion-mode device, channel doping is different to the doping in the source and drain junctions.

\section{RESULTS AND DISCUSSION}

The result of the research was obtained and dicussed in three forms:

\subsection{Impact of variation of $L_{G}$ on electrical characteristics of JLNWFET and Inversion mode FET}

JLNWFET and the inversion-mode devices were simulated at both linear and saturation regions which are $\mathrm{V}_{\mathrm{DS}}$ of $0.05 \mathrm{~V}$ and $1 \mathrm{~V}$ respectively. The $\mathrm{N}^{+}$region is heavily doped with concentration of $1 \times 10^{19} \mathrm{~cm}^{-3}$ in order to get high $\mathrm{ON}$-state current to flow between the source and the drain. A small cross section of the channel was used to ensure full depletion of the heavily doped channel resulting in low leakage current as shown in Figure 2. However, when Lg decreases, the leakage current increases. This is due to the short channel effects. Figure 2 shows the I-V curve of JLNWFET of for different $L_{G}$. It was found that the device with $L_{G}=120 \mathrm{~nm}$ has minimum $\mathrm{I}_{\mathrm{OFF}}$ while the device with smaller gate length, $\mathrm{L}_{\mathrm{G}}=7 \mathrm{~nm}$ has higher $\mathrm{I}_{\mathrm{OFF}}$. This prove that as the $\mathrm{I}_{\mathrm{OFF}}$ decreases with an increase of $\mathrm{L}_{\mathrm{G}}$. Figure 2 shows that JLNWFET with $\mathrm{L}_{\mathrm{G}}=7 \mathrm{~nm}$ has lower $\mathrm{V}_{\mathrm{TH}}$ while device with $\mathrm{L}_{\mathrm{G}}=120 \mathrm{~nm}$ has higher $\mathrm{V}_{\mathrm{TH}}$. This shows that as the $\mathrm{L}_{\mathrm{G}}$ increases, the $\mathrm{V}_{\mathrm{TH}}$ also increases and vice versa.

Figure 3 shows theSubthreshold slope and DIBL with $\mathrm{L}_{\mathrm{G}}$ variation for both devices. Subthreshold slope and DIBL in JLNWFET shows great improvement than the inversion-mode device as shown in Figure 3. Both the SS and DIBL were limited to $69.98 \mathrm{mV} / \mathrm{dec}$ and $54.73 \mathrm{mV} / \mathrm{V}$ respectively for $\mathrm{L}_{\mathrm{G}}$ of $7 \mathrm{~nm}$, compared to the inversion-mode device which has $90.13 \mathrm{mV} / \mathrm{dec}$ and $112.15 \mathrm{mV} / \mathrm{V}$ respectively for the same $\mathrm{L}_{\mathrm{G}}$. However, as the gate length LG increases with constant $\mathrm{dNW}$, the SS and DIBL reduced to the minimum level. For $\mathrm{L}_{\mathrm{G}}$ of $120 \mathrm{~nm}$, the SS and DIBL of JLNWFET device are $47.77 \mathrm{mV} / \mathrm{dec}$ and $69.98 \mathrm{mV} / \mathrm{V}$ respectively. Our aim is not only to minimize SCEs but also to improve the scaling in order to obtain the most optimum device structures with optimized electrical characteristics.

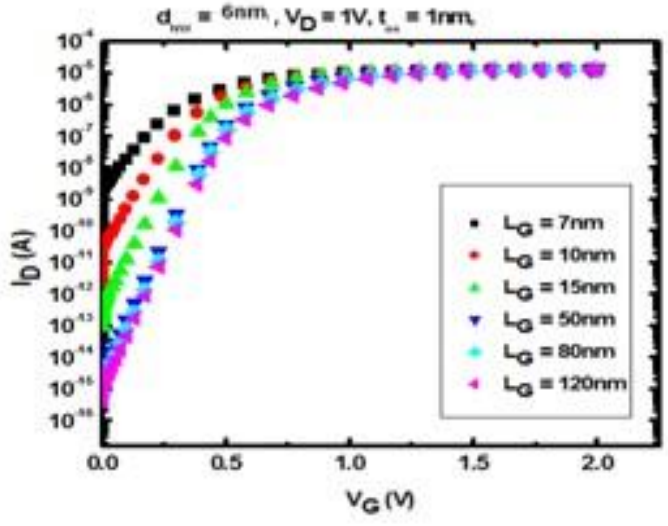

Figure 2. I-V characteristics of JLNWFET for different $L_{G}$ for $V_{D}=1 \mathrm{~V}$ (in $\log$ scale)

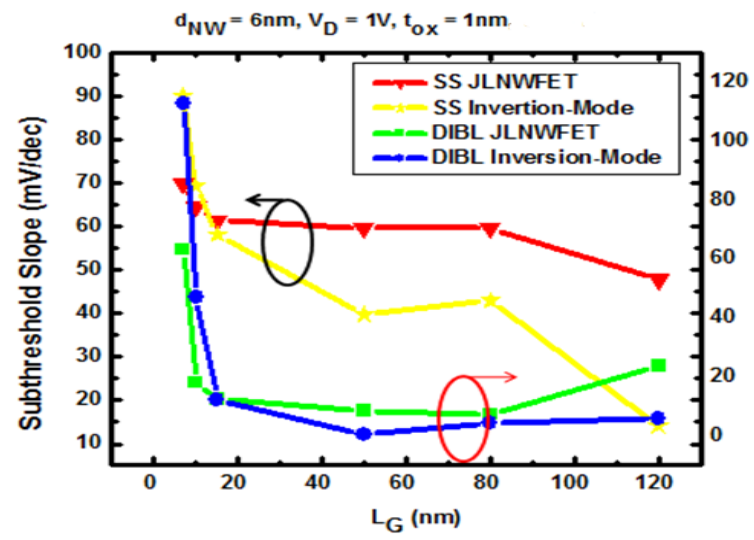

Figure 3. SS and DIBL of JLNWFET and inversionmode devices for different $\mathrm{L}_{\mathrm{G}}$ for $\mathrm{V}_{\mathrm{D}}=1 \mathrm{~V}$

High doping concentration, $\mathrm{N}_{\mathrm{D}}$ and small nanowire cross sectional area increases the ON-state current in nanowire junctionless transistor [23]. Metal gate work function and small cross-section area of the nanowire are to ensure full depletion of the heavily doped channel resulting in low leakage current [24]. Figure 4 shows JLNWFET and the Inversion-mode FET demonstrates almost equal ON-state current. For device with $\mathrm{L}_{\mathrm{G}}$ of 7 $\mathrm{nm}$, JLNWFET and the inversion-mode FET have $\mathrm{I}_{\mathrm{ON}}$ of $3.77 \times 10^{-6} \mathrm{~A}$ and $1.23 \times 10^{-5} \mathrm{~A}$ respectively. However, as the $\mathrm{L}_{\mathrm{G}}$ increases the $\mathrm{I}_{\mathrm{ON}}$ decreases. The OFF-state shows significant improvement in JLNWFET over the inversion-mode for gate length less or equal to $10 \mathrm{~nm}$. For $\mathrm{L}_{\mathrm{G}}$ of $7 \mathrm{~nm}$, IoFF is $8.68 \times 10^{-14} \mathrm{~A}$ and $2.50 \times 10^{-12} \mathrm{~A}$ for NW JLFET and inversion-mode device respectively. As the $\mathrm{L}_{\mathrm{G}}$ increases, the $\mathrm{I}_{\mathrm{OFF}}$ of both devices improves further. JLNWFET has better $\mathrm{I}_{\mathrm{ON}} / \mathrm{I}_{\mathrm{OFF}}$ ratio for $\mathrm{L}_{\mathrm{G}}$ below $10 \mathrm{~nm}$. For $\mathrm{L}_{\mathrm{G}}$ of $7 \mathrm{~nm}$, JLNWFET and inversionmode have $\mathrm{I}_{\mathrm{ON}} / \mathrm{I}_{\mathrm{OFF}}$ ratio of $4.34 \times 10^{7}$ and $4.92 \times 10^{6}$.

The results obtained were tabulated and compared as in the Table 2 for both JLNWFET and the inversion-mode devices. 
Table 2. Electrical propoerties of JLNWFET and Inversion-Mode for different $\mathrm{L}_{\mathrm{G}}$ with constant $\mathrm{d}_{\mathrm{NW}}$ of $6 \mathrm{~nm}$ for $\mathrm{V}_{\mathrm{D}}=\mathrm{V}_{\mathrm{G}}=1 \mathrm{~V}$

\begin{tabular}{c|ccccccc}
\multicolumn{1}{c}{ DEVICE } & $\mathrm{L}_{\mathrm{G}}(\mathrm{NM})$ & $\mathrm{V}_{\mathrm{TH}}(\mathrm{V})$ & $\mathrm{SS}(\mathrm{MV} / \mathrm{DEC})$ & DIBL $(\mathrm{MV} / \mathrm{V})$ & $\mathrm{I}_{\mathrm{ON}}(\mathrm{A})$ & $\mathrm{I}_{\mathrm{OFF}}(\mathrm{A})$ & $\mathrm{I}_{\mathrm{ON}} / \mathrm{I}_{\mathrm{OFF}}$ \\
\hline & 7 & 0.454 & 69.98 & 54.73 & $3.77 \times 10^{-6}$ & $8.68 \times 10^{-14}$ & $4.34 \times 10^{7}$ \\
& 10 & 0.503 & 64.71 & 24.10 & $3.70 \times 10^{-6}$ & $3.98 \times 10^{-15}$ & $9.29 \times 10^{8}$ \\
JLNWFET & 15 & 0.530 & 61.39 & 20.21 & $3.62 \times 10^{-6}$ & $3.75 \times 10^{-16}$ & $9.65 \times 10^{9}$ \\
& 50 & 0.584 & 59.53 & 17.58 & $3.11 \times 10^{-6}$ & $2.94 \times 10^{-17}$ & $1.06 \times 10^{11}$ \\
& 80 & 0.606 & 59.64 & 16.84 & $2.75 \times 10^{-6}$ & $1.75 \times 10^{-17}$ & $1.57 \times 10^{11}$ \\
& 120 & 0.622 & 47.77 & 27.89 & $2.34 \times 10^{-6}$ & $1.11 \times 10^{-17}$ & $2.11 \times 10^{11}$ \\
\hline & 7 & 0.443 & 90.13 & 112.95 & $1.23 \times 10^{-5}$ & $2.50 \times 10^{-12}$ & $4.29 \times 10^{6}$ \\
INVERSION- & 10 & 0.554 & 69.29 & 47.26 & $1.07 \times 10^{-5}$ & $2.39 \times 10^{-15}$ & $4.48 \times 10^{6}$ \\
MODE & 15 & 0.604 & 58.15 & 12.42 & $1.02 \times 10^{-5}$ & $3.94 \times 10^{-17}$ & $2.59 \times 10^{11}$ \\
& 50 & 0.648 & 39.71 & 8.29 & $7.50 \times 10^{-6}$ & $4.87 \times 10^{-18}$ & $1.54 \times 10^{12}$ \\
& 80 & 0.656 & 42.97 & 4.32 & $6.21 \times 10^{-6}$ & $2.79 \times 10^{-18}$ & $2.23 \times 10^{12}$ \\
& 120 & 0.666 & 14.06 & 5.89 & $5.12 \times 10^{-6}$ & $2.59 \times 10^{-18}$ & $1.98 \times 10^{12}$
\end{tabular}

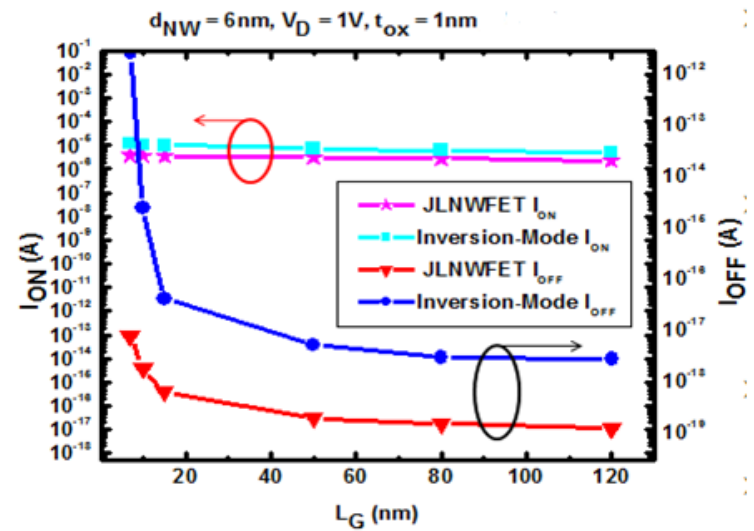

Figure 4. $\mathrm{I}_{\mathrm{ON}}$ and $\mathrm{I}_{\mathrm{OFF}}$ of JLNWFET and inversion-mode device for different $\mathrm{L}_{\mathrm{G}}$ for $\mathrm{V}_{\mathrm{D}}=1 \mathrm{~V}$

\subsection{Impact of variation of $d_{N W}$ on electrical characteristics of JLNWFET and Inversion mode FET}

JLNWFET and the inversion-mode devices were simulated using different $\mathrm{d}_{\mathrm{NW}}$ of 6,8 , and $10 \mathrm{~nm}$ using a constant $\mathrm{L}_{\mathrm{G}}$ of $\mathrm{V}_{\mathrm{D}}$ of $1 \mathrm{~V}$. For $\mathrm{d}_{\mathrm{NW}}$ of $6 \mathrm{~nm}$, JLNWFET and inversion-mode has $\mathrm{V}_{\mathrm{TH}}$ of $0.454 \mathrm{~V}$ and $0.443 \mathrm{~V}$ respectively. However, as the diameter increases, the threshold voltage decreases for both the two devices because, the $\mathrm{V}_{\mathrm{TH}}$ depends on the doping concentration, gate oxide thickness, nanowire width and silicon thickness film [25]. The DIBL and the SS shows significant improvement in JLNWFET than in the inversion-mode device as shown in Figure 5. For $\mathrm{d}_{\mathrm{NW}}$ of $6 \mathrm{~nm}$, the SS and DIBL of JLNWFET and inversion mode are $69.98 \mathrm{mV} / \mathrm{dec}$ and $54.74 \mathrm{mV} / \mathrm{V}$ respectively as against the inversion-mode FET of $90.13 \mathrm{mV} / \mathrm{dec}$ and $112.15 \mathrm{mV} / \mathrm{V}$ respectively. Nevertheless, as the $\mathrm{d}_{\mathrm{NW}}$ increases both the SS and DIBL increases further

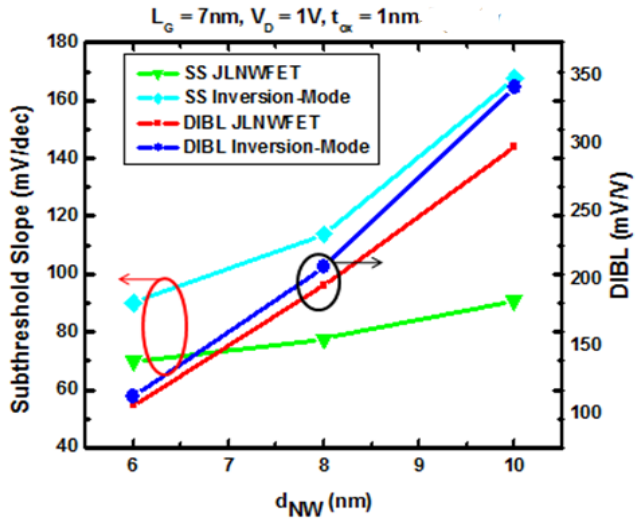

Figure 5. DIBL and SS of JLNWFET and inversion-mode device for different $\mathrm{d}_{\mathrm{NW}}$ for $\mathrm{V}_{\mathrm{D}}$ of 1 V.

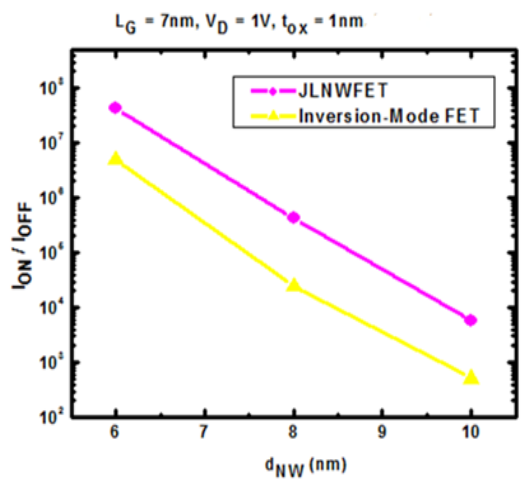

Figure 6. $\mathrm{I}_{\mathrm{ON}} / \mathrm{I}_{\mathrm{OFF}}$ of NW JLFET and inversionmode device for different $d_{N W}$ for $V_{D}$ of $1 \mathrm{~V}$ 
Small $\mathrm{d}_{\mathrm{NW}}$ and high doping and concentration reduce the series resistance for the flow of current in nanowire, hence increasing the ON-state current of the junctioless transistor [16]. Metal gate material was used in order to reduce the gate resistance. Small cross section of the channel allows the gate to deplete the heavily doped channel entirely and obtain a very low leakage current $\left(\mathrm{I}_{\mathrm{OFF}}\right)$ [9].Figure 6 shows the JLNWFET exhibits higher ON-state to OFF-state current ratio than the inversion-mode device. For $\mathrm{d}_{\mathrm{NW}}$ of $6 \mathrm{~nm}$, I $\mathrm{I}_{\mathrm{ON}} / \mathrm{I}_{\mathrm{OFF}}$ of JLNWFET and inversion-mode were found to be $4.34 \times 10^{7}$ and $4.92 \times 10^{6}$ respectively. Nevertheless, as the $\mathrm{d}_{\mathrm{NW}}$ increases the $\mathrm{I}_{\mathrm{ON}} / \mathrm{I}_{\mathrm{OFF}}$ of both the two devices decreases. This proves that, high doping concentration and small cross-sectional area of nanowire improve the performance of the device. The results of the variation of nanowire diameter $\left(\mathrm{d}_{\mathrm{NW}}\right)$ for $\mathrm{L}_{\mathrm{G}}$ of $7 \mathrm{~nm}$ of both JLNWFET and the inversion-mode devices were obtained and tabulated in Table 3.

Table 3. Electrical Characteristics of JLNWFET and Inversion-Mode for constant $\mathrm{L}_{\mathrm{G}}$ of $7 \mathrm{~nm}$ with different $\mathrm{d}_{\mathrm{NW}}$ for $\mathrm{V}_{\mathrm{D}}=\mathrm{V}_{\mathrm{G}}=1 \mathrm{~V}$

\begin{tabular}{c|ccccccc} 
DEVICE & $\mathrm{D}_{\mathrm{NW}}(\mathrm{nm})$ & $\mathrm{V}_{\mathrm{TH}}(\mathrm{V})$ & $\mathrm{SS}(\mathrm{mV} / \mathrm{dec})$ & $\mathrm{DIBL}(\mathrm{mV} / \mathrm{V})$ & $\mathrm{I}_{\mathrm{ON}}(\mathrm{A})$ & $\mathrm{I}_{\mathrm{OFF}}(\mathrm{A})$ & $\mathrm{I}_{\mathrm{ON}} / \mathrm{I}_{\mathrm{OFF}}$ \\
\hline & 6 & 0.454 & 69.98 & 54.73 & $3.77 \times 10^{-6}$ & $8.68 \times 10^{-14}$ & $4.34 \times 10^{7}$ \\
JLNWFET & 8 & 0.320 & 77.59 & 96.11 & $6.64 \times 10^{-6}$ & $1.56 \times 10^{-11}$ & $4.26 \times 10^{5}$ \\
& 10 & 0.168 & 90.91 & 143.89 & $1.03 \times 10^{-5}$ & $1.84 \times 10^{-9}$ & $5.60 \times 10^{3}$ \\
\hline \multirow{2}{*}{ INVERSION- } & 6 & 0.443 & 90.13 & 112.95 & $1.23 \times 10^{-5}$ & $2.50 \times 10^{-12}$ & $4.29 \times 10^{6}$ \\
MODE & 8 & 0.269 & 113.75 & 209.16 & $1.90 \times 10^{-5}$ & $7.84 \times 10^{-10}$ & $2.44 \times 10^{4}$ \\
& 10 & 0.046 & 167.50 & 341.89 & $2.73 \times 10^{-5}$ & $5.32 \times 10^{-8}$ & $5.12 \times 10^{2}$
\end{tabular}

\subsection{Effects of different dielectric materials of the electrical characteristic of JLNWFET}

'To optimize the device, JLNWFETs was designed and simulated with different dielectric materials; $\mathrm{HfO}_{2}, \mathrm{Si}_{3} \mathrm{~N}_{4}$ and $\mathrm{SiO} 2$ of different $\mathrm{L}_{\mathrm{G}}$ as in [26]. The remaining parameters and dimensions are the same as in Table 1. The electrical characteristics of the devices was obtained using Sdevice of Sentaurus TCAD, analyzed and compared.

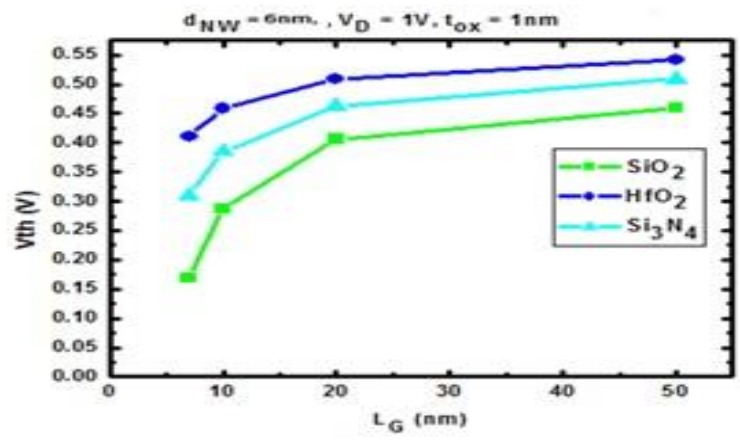

Figure 7. $\mathrm{V}_{\mathrm{TH}}$ of JLNWFETs for different dielectric materials for $\mathrm{V}_{\mathrm{D}}$ of $1 \mathrm{~V}$

Figure 7shows the $\mathrm{V}_{\mathrm{TH}}$ of the JLNWFET of the three different oxide materials for different $\mathrm{L}_{\mathrm{G}}$ was shown. It was found out that $\mathrm{SiO}_{2}$ demonstrates lower $\mathrm{V}_{\mathrm{TH}}$ of all $\mathrm{L}_{\mathrm{G}}$. For $\mathrm{L}_{\mathrm{G}}$ of $7 \mathrm{~nm}$, threshold voltage of the JLNWFET with $\mathrm{SiO}_{2}, \mathrm{HfO}_{2}$ and $\mathrm{Si}_{3} \mathrm{~N}_{4}$ are $0.169 \mathrm{~V}$ compared to $0.410 \mathrm{~V}$ and $0.310 \mathrm{~V}$ of respectively. As the $\mathrm{L}_{\mathrm{G}}$ increases $\mathrm{V}_{\mathrm{TH}}$ also increases in all the three devices as shown.

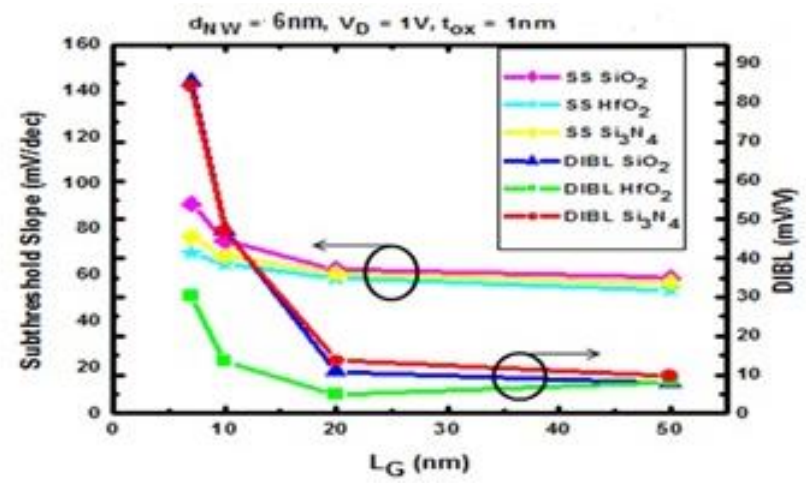

Figure 8. Effect of different dielectric materials on SS and DIBL of JLNWFET for different $\mathrm{L}_{\mathrm{G}}$ 
Junctionless transistors are expected to have a very low DIBL and SS effects due to the absent of junction. When $\mathrm{L}_{\mathrm{G}}$ is small, high- $k$ dielectrics can help to minimize this DIBL effect very effectively. The theoretical limit of SS is $60 \mathrm{mV} /$ decade [26]. In Figure 8, it was found out that $\mathrm{HfO}_{2}$ exhibits better SS and DIBL among the three gate oxides. For $\mathrm{L}_{\mathrm{G}}$ of $10 \mathrm{~nm}$, the $\mathrm{SS}$ and DIBL of $\mathrm{HfO}_{2}, \mathrm{SiO}_{2}$ and $\mathrm{Si}_{3} \mathrm{~N}_{4}$ are 64.70 $\mathrm{mV} / \mathrm{dec}$ and $22.74 \mathrm{mV} / \mathrm{V}, 74.92 \mathrm{mV} / \mathrm{dec}$ and $79.68 \mathrm{mV} / \mathrm{V}$ and $68.49 \mathrm{mV} / \mathrm{dec}$ and $46.95 \mathrm{mV} / \mathrm{V}$ respectively. JLNWFET demonstrates lower $\mathrm{I}_{\mathrm{OFF}}$ when the $\mathrm{L}_{\mathrm{G}}$ is large. For $\mathrm{L}_{\mathrm{G}}$ of $50 \mathrm{~nm}$, the $\mathrm{I}_{\mathrm{OFF}}$ of $\mathrm{SiO}_{2}, \mathrm{HfO}_{2}$ and $\mathrm{Si}_{3} \mathrm{~N}_{4}$ are $3.81 \times 10^{-15} \mathrm{~A}, 1.14 \times 10^{-16} \mathrm{~A}$ and $4.92 \times 10^{-16} \mathrm{~A}$ respectively. For device with $\mathrm{L}_{\mathrm{G}} 7 \mathrm{~nm}$, the OFF-state currents are high i.e. $1.84 \times 10^{-9} \mathrm{~A}, 2.66 \times 10^{-13} \mathrm{~A}$ and $1.76 \times 10^{-11} \mathrm{~A}$ for $\mathrm{SiO}_{2}, \mathrm{HfO}_{2}$ and $\mathrm{Si}_{3} \mathrm{~N}_{4}$ respectively. $\mathrm{HfO}_{2}$ reveals better OFF-state current than the other two dielectric materials.

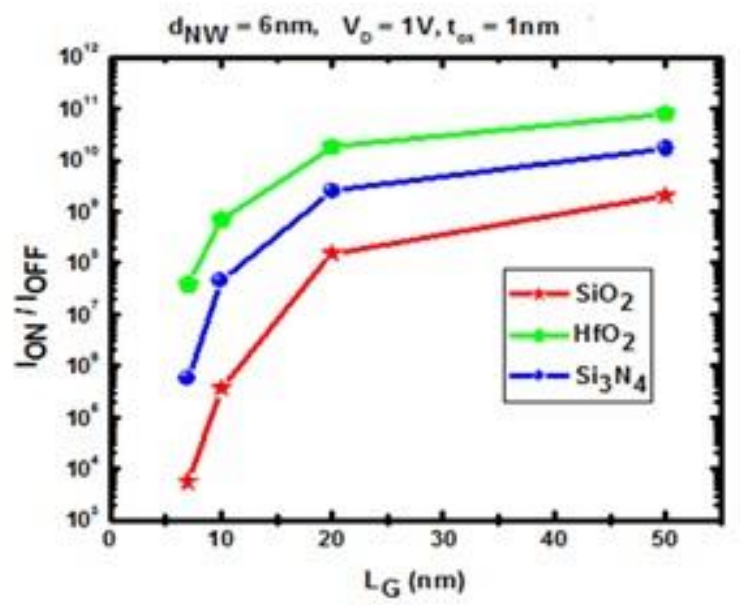

Figure 9. Effect of different dielectric materials on $\mathrm{I}_{\mathrm{ON}} / \mathrm{I}_{\mathrm{OFF}}$ of JLNWFET of different $\mathrm{L}_{\mathrm{G}}$ for $\mathrm{V}_{\mathrm{D}}$ of $1 \mathrm{~V}$

Due to the higher $\mathrm{I}_{\mathrm{ON}}$ and lower $\mathrm{I}_{\mathrm{OFF}}$, $\mathrm{HfO}_{2}$ exhibits higher $\mathrm{ON}$-state to OFF-state current ratio as shown in Figure 9. For devices with $\mathrm{L}_{\mathrm{G}} 10 \mathrm{~nm}, \mathrm{I}_{\mathrm{ON}} / \mathrm{I}_{\mathrm{OFF}}$ of $\mathrm{SiO}_{2}, \mathrm{HfO}_{2}$ and $\mathrm{Si}_{3} \mathrm{~N}_{4}$ was found to be $3.70 \times 105$, $6.96 \times 108$ and $4.43 \times 107$ respectively. The $\mathrm{I}_{\mathrm{ON}} / \mathrm{I}_{\mathrm{OFF}}$ increases when the gate length increases. The $\mathrm{I}_{\mathrm{ON}} / \mathrm{I}_{\mathrm{OFF}}$ of $\mathrm{SiO}_{2}, \mathrm{HfO}_{2}$ and $\mathrm{Si}_{3} \mathrm{~N}_{4}$ when $\mathrm{L}_{\mathrm{G}}$ is $50 \mathrm{~nm}$ are 2.04 × $109,7.88$ × 1010 and 1.68 x 1010 respectively. The results obtained were tabulated and compared in the Table 4 for the devices with three different dielectric materials.

Table 4. Electrical Characteristics of JLNWFET for constant $d_{N W}$ of $6 \mathrm{~nm}$ with different $\mathrm{L}_{\mathrm{G}}$ for $\mathrm{V}_{\mathrm{D}}$ of $1 \mathrm{~V}$

\begin{tabular}{|c|c|c|c|c|c|c|c|c|}
\hline DEVICE & $\begin{array}{l}\text { GATE } \\
\text { OXIDE }\end{array}$ & $\mathrm{L}_{\mathrm{G}}(\mathrm{nm})$ & $\mathrm{V}_{\mathrm{TH}}(\mathrm{V})$ & $\begin{array}{c}\mathrm{SS} \\
(\mathrm{mV} / \mathrm{dec})\end{array}$ & $\begin{array}{c}\text { DIBL } \\
(\mathrm{mV} / \mathrm{V})\end{array}$ & $\mathrm{I}_{\mathrm{ON}}(\mathrm{A})$ & $\mathrm{I}_{\mathrm{OFF}}(\mathrm{A})$ & $\mathrm{I}_{\mathrm{ON}} / \mathrm{I}_{\mathrm{OFF}}$ \\
\hline \multirow{12}{*}{ JLNWFET } & \multirow{4}{*}{$\mathrm{SiO}_{2}$} & 7 & 0.169 & 90.91 & 143.89 & $1.03 \times 10^{-5}$ & $1.84 \times 10^{-9}$ & $5.60 \times 10^{3}$ \\
\hline & & 10 & 0.287 & 74.92 & 79.68 & $1.00 \times 10^{-5}$ & $2.70 \times 10^{-11}$ & $3.70 \times 10^{5}$ \\
\hline & & 20 & 0.320 & 62.45 & 18.21 & $9.38 \times 10^{-6}$ & $6.09 \times 10^{-14}$ & $1.54 \times 10^{8}$ \\
\hline & & 50 & 0.168 & 58.95 & 13.16 & $7.74 \times 10^{-6}$ & $3.81 \times 10^{-15}$ & $2.04 \times 10^{9}$ \\
\hline & \multirow{4}{*}{$\mathrm{HfO}_{2}$} & 7 & 0.410 & 69.67 & 51.16 & $1.04 \times 10^{-5}$ & $2.66 \times 10^{-13}$ & $3.91 \times 10^{7}$ \\
\hline & & 10 & 0.459 & 64.70 & 22.74 & $1.03 \times 10^{-5}$ & $1.48 \times 10^{-14}$ & $6.96 \times 10^{8}$ \\
\hline & & 20 & 0.508 & 58.76 & 8.21 & $9.89 \times 10^{-6}$ & $5.49 \times 10^{-16}$ & $1.80 \times 10^{10}$ \\
\hline & & 50 & 0.542 & 53.72 & 13.79 & $8.98 \times 10^{-6}$ & $1.14 \times 10^{-16}$ & $7.88 \times 10^{10}$ \\
\hline & \multirow{4}{*}{$\mathrm{Si}_{3} \mathrm{~N}_{4}$} & 7 & 0.310 & 76.71 & 84.32 & $1.03 \times 10^{-5}$ & $1.76 \times 10^{-11}$ & $5.85 \times 10^{5}$ \\
\hline & & 10 & 0.385 & 68.49 & 46.95 & $1.01 \times 10^{-5}$ & $2.28 \times 10^{-13}$ & $4.43 \times 10^{7}$ \\
\hline & & 20 & 0.463 & 60.69 & 13.58 & $9.59 \times 10^{-6}$ & $3.86 \times 10^{-15}$ & $2.48 \times 10^{9}$ \\
\hline & & 50 & 0.509 & 56.89 & 9.58 & $8.29 \times 10^{-6}$ & $4.92 \times 10^{-16}$ & $1.68 \times 10^{10}$ \\
\hline
\end{tabular}

Table 5. Performance validation of proposed work and other works

\begin{tabular}{c|ccccc} 
Electrical & \multicolumn{3}{c}{$\mathrm{L}_{\mathrm{G}}=7 \mathrm{~nm}$} & $\mathrm{~L}_{\mathrm{G}}=20 \mathrm{~nm}$ \\
\cline { 2 - 6 } Properties & {$[27]$} & This Work & {$[27]$} & {$[27]$} & This Work \\
$\mathrm{SS}(\mathrm{mV} / \mathrm{dec})$ & 68.5 & 54.73 & 61.68 & 110 & 62.45 \\
DIBL $(\mathrm{mV} / \mathrm{V})$ & 17.3 & 69.98 & 30 & 140 & 18.21 \\
$\mathrm{I}_{\mathrm{ON}}(\mathrm{A})$ & N/A & N/A & $7 \times 10^{-6}$ & N/A & $9.38 \times 10^{-6}$ \\
$\mathrm{I}_{\mathrm{ON}} / \mathrm{I}_{\mathrm{OFF}}$ & $10^{6}$ & $10^{7}$ & $10^{7}$ & $10^{5}$ & $10^{8}$
\end{tabular}


The highlighted result (in red box) in Table 4 shows the electrical characteristics of $\mathrm{HfO}_{2}$. It was found out that $\mathrm{HfO}_{2}$ exhibits significant characteristics than $\mathrm{SiO}_{2}$ and $\mathrm{Si}_{3} \mathrm{~N}_{4}$. It can be observed that for $\mathrm{L}_{\mathrm{G}}$ of $7 \mathrm{~nm}, \mathrm{HfO}_{2}$ has achieved $\mathrm{I}_{\mathrm{ON}} / \mathrm{I}_{\mathrm{OFF}}$ of $10^{7}$ compared to $\mathrm{SiO}_{2}$ and $\mathrm{Si}_{3} \mathrm{~N}_{4}$ of $10^{3}$ and $10^{5}$ respectively. SS and DIBL were highly improved to $64.70 \mathrm{mV} / \mathrm{dec}$. and $22.74 \mathrm{mV} / \mathrm{V}$ respectively for $\mathrm{L}_{\mathrm{G}}$ of $7 \mathrm{~nm}$ in $\mathrm{HfO}_{2}$ than the other two materials. This shows that the proposed JLNWFET with $\mathrm{HfO}_{2}$ is the optimum alternative to improve the scaling and the performance of the device as well as to suppress the SCEs.The electrical properties of this proposed work was compared with the other works in $[4,8,11]$ for $\mathrm{L}_{\mathrm{G}}$ of $7 \mathrm{~nm}$ and $20 \mathrm{~nm}$ as in Table 5. For the case of $7 \mathrm{~nm}$ gate length, it was observed that SS of this proposed work is improved by $20 \%$ with 54.7 $\mathrm{mV} / \mathrm{dec}$ as compared to $68.5 \mathrm{mV} / \mathrm{dec}$. $\mathrm{I}_{\mathrm{ON}} / \mathrm{I}_{\mathrm{OFF}}$ is also improved by tenfold as compared to [4]. For the case of $20 \mathrm{~nm}$ gate length, it was observed that but the DIBL is greatly improved by about $39 \%$ with $18.21 \mathrm{mV} / \mathrm{V}$ as compared to [8] which is $30 \mathrm{mV} / \mathrm{V}$. Moreover, for the case of $20 \mathrm{~nm}$ gate length, it was observed that SS, DIBL and $\mathrm{I}_{\mathrm{ON}} / \mathrm{I}_{\mathrm{OFF}}$ are greatly improved if compared to [11].

\section{CONCLUSION}

JLNWFET and inversion-mode devices have been successfully designed for different gate lengths and nanowire diameters. The electrical characteristics of the two devices was compared and analyzed. The electrical characteristics and performance of JLNWFET of three different dielectric materials (low-k and highk) have been investigated, compared and analyzed. This work discovered that JLNWFET exhibits significant improvement in electrical characteristics than the inversion-mode device especially for gate length less or equal to $10 \mathrm{~nm}$. SCEs such as DIBL and SS are considerably reduced in JLNWFET devices. Although, the JLNWFET with long $\mathrm{L}_{\mathrm{G}}$ demonstrated higher $\mathrm{I}_{\mathrm{ON}} / \mathrm{I}_{\mathrm{OFF}}$ and the most optimum SCEs. Our aim is not only to improve performance and SCEs, but also to get the most optimum device's physical parameter. For the same $\mathrm{L}_{\mathrm{G}}$ and $\mathrm{d}_{\mathrm{NW}}$, JLNWFET proved to have better electrical characteristics than the inversion-mode device. JLNWFET with $\mathrm{HfO}_{2}$ dielectric demonstrated better SCEs and excellent electrical characteristics than JLNWFET with $\mathrm{Si}_{3} \mathrm{~N}_{4}$ and $\mathrm{SiO}_{2}$ dielectrics for $\mathrm{L}_{\mathrm{G}}$ shorter than $35 \mathrm{~nm}$. JLNWFET with $\mathrm{Si}_{3} \mathrm{~N}_{4}$ exhibits better electrical characteristics and SCEs than $\mathrm{HfO}_{2}$ and $\mathrm{SiO}_{2}$ for gate length longer than $35 \mathrm{~nm}$. To achieve better performance, JLNWFET of $\mathrm{L}_{\mathrm{G}} 10 \mathrm{~nm}$ or below is highly recommended. Heavily doped concentration and small nanowire diameter $\left(\mathrm{d}_{\mathrm{NW}}\right)$ of $10 \mathrm{~nm}$ or below produced higher $\mathrm{ON}$-state current. Metal gate material was used to reduce gate resistance. To achieve volume depletion, the cross-sectional area of the channel must be small enough in order to deplete the highly doped channel entirely. In both the JLNWFET and the inversion-mode devices, as the ON-state current increases, the OFF-state current also increases which leads to small improvement in the $\mathrm{I}_{\mathrm{ON}} / \mathrm{I}_{\mathrm{OFF}}$ ratio.

\section{ACKNOWLEDGMENTS}

Authors would like to acknowledge the financial support of the Ministry of Higher Education (MOHE), Malaysia under the Research University Grant (GUP) Project No. Q.J130000.2651.16J19. Also, thanks to the Research Management Center (RMC) of Universiti Teknologi Malaysia (UTM) for providing an excellent research environment in which to complete this work.

\section{REFERENCES}

[1] K. J. Kuhn, "Moore's Law Past 32nm: Future Challenges in Device Scaling," in Computational Electronics, 2009. IWCE'09. 13th International Workshop on, 2009, pp. 1-6: IEEE.

[2] M. Lundstrom, "Moore's law forever?," Science, vol. 299, no. 5604, pp. 210-211, 2003.

[3] L.-C. Chen et al., "The physical analysis on electrical junction of junctionless FET," AIP Advances, vol. 7, no. 2, p. 025301, 2017.

[4] J.-P. Colinge et al., "Nanowire transistors without junctions," Nature nanotechnology, vol. 5, no. 3, p. $225,2010$.

[5] C. Osburn, "Formation of silicided, ultra-shallow junctions using low thermal budget processing," Journal of Electronic Materials, vol. 19, no. 1, pp. 67-88, 1990.

[6] E. Gnani, A. Gnudi, S. Reggiani, and G. Baccarani, "Theory of the junctionless nanowire FET," IEEE Transactions on Electron Devices, vol. 58, no. 9, pp. 2903-2910, 2011.

[7] G. Mariniello, R. T. Doria, M. de Souza, M. A. Pavanello, and R. D. Trevisoli, "Analysis of gate capacitance of n-type junctionless transistors using three-dimensional device simulations," in 2012 8th International Caribbean Conference on Devices, Circuits and Systems (ICCDCS), 2012, pp. 1-4: IEEE.

[8] S. Saurabh and M. J. Kumar, Fundamentals of tunnel field-effect transistors. CRC Press, 2016.

[9] C.-W. Lee, A. Afzalian, N. D. Akhavan, R. Yan, I. Ferain, and J.-P. Colinge, "Junctionless multigate field-effect transistor," Applied Physics Letters, vol. 94, no. 5, p. 053511, 2009.

[10] J. K. Mamidala, R. Vishnoi, and P. Pandey, Tunnel field-effect transistors (TFET): modelling and simulation. John Wiley \& Sons, 2016. 
[11] M.A. Riyadi, I.D. Sukawati, T. Prakoso, Darjat, " Influence of gate material and process on junctionless FET subthreshold performance" International Journal of Electrical and Computer Engineering, vol. 6 no. 2, pp. 895900, 2016.

[12] S. Das and S. Kundu, "A Review on Junctionless Transistor-A Prospective sub-10nm Logic Device," Advanced Research in Electrical and Electronic Engineering, vol. 1, no. 3, pp. 98-102, 2014.

[13] D. Amuru, K. Ragini, and P. C. Reddy, "Emerging NanoFETs and Electrostatics Influencing Nanoscale Transistors: A Review," International Journal of Engineering and Applied Sciences, vol. 3, no. 2.

[14] N. R. Mohapatra, M. P. Desai, S. G. Narendra, and V. R. Rao, "The effect of high-k gate dielectrics on deep submicrometer CMOS device and circuit performance," IEEE Transactions on Electron Devices, vol. 49, no. 5, pp. 826-831, 2002.

[15] J. Colinge et al., "Junctionless nanowire transistor (JNT): Properties and design guidelines," Solid-State Electronics, vol. 65, pp. 33-37, 2011.

[16] S. Sahay and M. J. Kumar, "Controlling L-BTBT and volume depletion in nanowire JLFETs using core-shell architecture," IEEE Transactions on Electron Devices, vol. 63, no. 9, pp. 3790-3794, 2016.

[17] R. K. Baruah and R. P. Paily, "Impact of high-k spacer on device performance of a junctionless transistor," Journal of Computational Electronics, vol. 12, no. 1, pp. 14-19, 2013.

[18] S. Gundapaneni, M. Bajaj, R. K. Pandey, K. V. Murali, S. Ganguly, and A. Kottantharayil, "Effect of band-toband tunneling on junctionless transistors," IEEE Transactions on Electron Devices, vol. 59, no. 4, pp. 1023$1029,2012$.

[19] S. Gundapaneni, S. Ganguly, and A. Kottantharayil, "Enhanced Electrostatic Integrity of Short-Channel Junctionless Transistor With High-\$kappa \$ Spacers," IEEE Electron Device Letters, vol. 32, no. 10, pp. 13251327, 2011.

[20] A. Kranti et al., "Junctionless nanowire transistor (JNT): Properties and design guidelines," in 2010 Proceedings of the European Solid State Device Research Conference, 2010, pp. 357-360: IEEE.

[21] S. Sahay and M. J. Kumar, "Symmetric operation in an extended back gate JLFET for scaling to the 5-nm regime considering quantum confinement effects," IEEE Transactions on Electron Devices, vol. 64, no. 1, pp. 21-27, 2016.

[22] S. Sahay and M. J. Kumar, "Nanotube junctionless FET: Proposal, design, and investigation," IEEE Transactions on Electron Devices, vol. 64, no. 4, pp. 1851-1856, 2017.

[23] J.-P. Colinge et al., "Junctionless nanowire transistor: complementary metal-oxide-semiconductor without junctions," Science of Advanced Materials, vol. 3, no. 3, pp. 477-482, 2011

[24] C.-H. Park et al., "Electrical characteristics of 20-nm junctionless Si nanowire transistors," Solid-State Electronics, vol. 73, pp. 7-10, 2012.

[25] A. Nazarov, J. Colinge, F. Balestra, J.-P. Raskin, F. Gamiz, and V. Lysenko, Semiconductor-on-insulator materials for nanoelectronics applications. Springer, 2011.

[26] A. Al Sayem, Y. Arafat, and M. M. Rahman, "Effect of high k-dielectric as gate oxide on short channel effects of junction-less transistor," in 2013 2nd International Conference on Advances in Electrical Engineering (ICAEE), 2013, pp. 115-118: IEEE.

[27] S. Sahay and M. J. Kumar, "Diameter dependence of leakage current in nanowire junctionless field effect transistors," IEEE Transactions on Electron Devices, vol. 64, no. 3, pp. 1330-1335, 2017. 